\title{
Spino-Cerebello-Cerebral Degeneration with Amyloid Plaques (Gerstmann, Sträussler, Scheinker Syndrome)
}

\author{
CLARISSE L. DOLMAN and LYLE L. DALY
}

SUMMARY: We report the case of a man who died at age 40 after $a 9$ year illness resembling $a$ hereditary spinocerebellar degeneration, but accompanied also by brain stem signs and dementia. Autopsy disclosed lesions of combined spinocerebellar and ponto-cerebellar degenera-

RESUME: Nous réportons un patient qui est mort à 40 ans après une maladie des 9 ans, que réssemblait à une dégénération spinale-cérébelleuse héréditaire, mais que était accompagnée aussi par les symptoms bulbairs et la demence. Beaucoup des plaques amyloides frappantes sont disseminees tion, but also damage to many brain stem nuclei. Prominent amyloid plaques disseminated through the brain indicated a relationship to the Kuru-Creutzfeldt-Jakob group of diseases. Transmission experiments are underway at the National Institutes of Health.

au cerveau et ce faisait la connection avec la groupe des maladies genre Kuru et Creutzfeldt-Jakob. Des experiments pour transmettre la maladie aux animaux ont été commencées a les Institutes Nationales de la Santé(E.U.).
Gerstmann, Sträussler and Scheinker reported in 1936 a familial disease which combined clinical features of Friedreich's ataxia, ponto-cerebellar degeneration and dementia. Further members of this family from Lower Austria were later studied by von Braunmühl (1954) and Seitelberger (1962). The disease was inherited as autosomal dominant and the pathology was noteworthy in showing amyloid plaques in addition to degeneration of the spino-ponto-cerebellar systems. The present report describes a Canadian patient with this disease.

\section{CASE REPORT:}

This man of Scottish ancestry was born in Ontario. Two paternal uncles and a brother, who was murdered in his early twenties, were said to have had symptoms similar to those the patient later developed. He was a dull student, left school at 16 years, but held a job as doorhanger until he was disabled. He had undescended testicles and at age 20 an intra-abdominal seminoma was removed, followed by irradiation.

At 31 years, he began to have episodes of slight slurring of speech and a staggering gait. This progressed slowly and 3 years later, he was found to have nystagmus in all directions, ataxia and Babinski reflexes. EEG, air studies and CSF were normal. A diagnosis of multiple sclerosis was made.

By the age of 36 he could no longer work because of balance problems. He had urinary frequency, episodes of tinnitus and occasional double vision. He was mentally alert, though of low intelligence. A high arched palate and pes cavus deformities of the feet were noted. Vision, fields and eye grounds were normal. He had vertical and horizontal nystagmus and slurring dysarthria. Hearing was normal. Motor power was slightly diminished in the limb-girdles, sensation was normal. He had moderate truncal ataxia and the 
gait was wide-based and staggering. Finger-nose tests were well performed but the hands were strikingly clumsy and rapid alternating movements were poorly executed. The heel-shin test was done very badly. The Romberg test was normal. The knee and ankle jerks were absent and the plantar responses were bilaterally extensor. Laboratory tests, including chest and skull $x$-rays, EEG, blood and urine analysis and renal function tests, were normal. A diagnosis of Friedreich's ataxia was made and the patient was enrolled in a program of occupational, speech and physiotherapy.

During the next 3 years the patient became wheelchair bound and then bedridden and had to be confined to an extended care unit. He was alert but had become a behavior problem, occasionally smearing stool over the bathroom, throwing his urinal around and moaning horribly. Some of this may have been due to his incoordination and difficulty in speaking. His speech was unintelligible and he was deaf, but he could obey simple motor commands when they were shouted loudly. He could not feed himself because of incoordination, had difficulty in chewing and swallowing and had frequent choking spells. His fields were full to threat, pupils were equal and reactive. He had a bilateral inter- nuclear ophthalmoplegia and some additional restriction of abduction. Facial symmetry was normal but the features were contorted into a constant snarl and he could not lift his upper lip, nor open his jaws wide. He could just protrude his tongue to his lips but other movements of the tongue were normal. He was areflexic except for increased jaw jerk and gag reflexes and bilateral Babinski responses. His upper limbs were markedly ataxic and hypotonic, but strength and sensation to pinprick were normal. The lower extremities showed a spastic paraparesis, with only slight increase in tone. The legs were held in extension with the feet inverted and plantarflexed, and he could not lift them off the bed. He remained a difficult nursing problem and died at age 40 , of pneumonia and gastric dilatation. Myoclonus was never observed during the course of his illness.

\section{Neuropathology}

The formalin fixed brain, which weighed 1460 gms., and the spinal cord were received. The cerebellum and brain stem were shrunken (Fig. 1). The basis pontis was diminished, the middle and inferior cerebellar peduncles very small, the dentate nucleus hardly visible and the superior cerebellar peduncles not visible at all. The aqueduct and 4 th ventricle were dilated. In the spinal

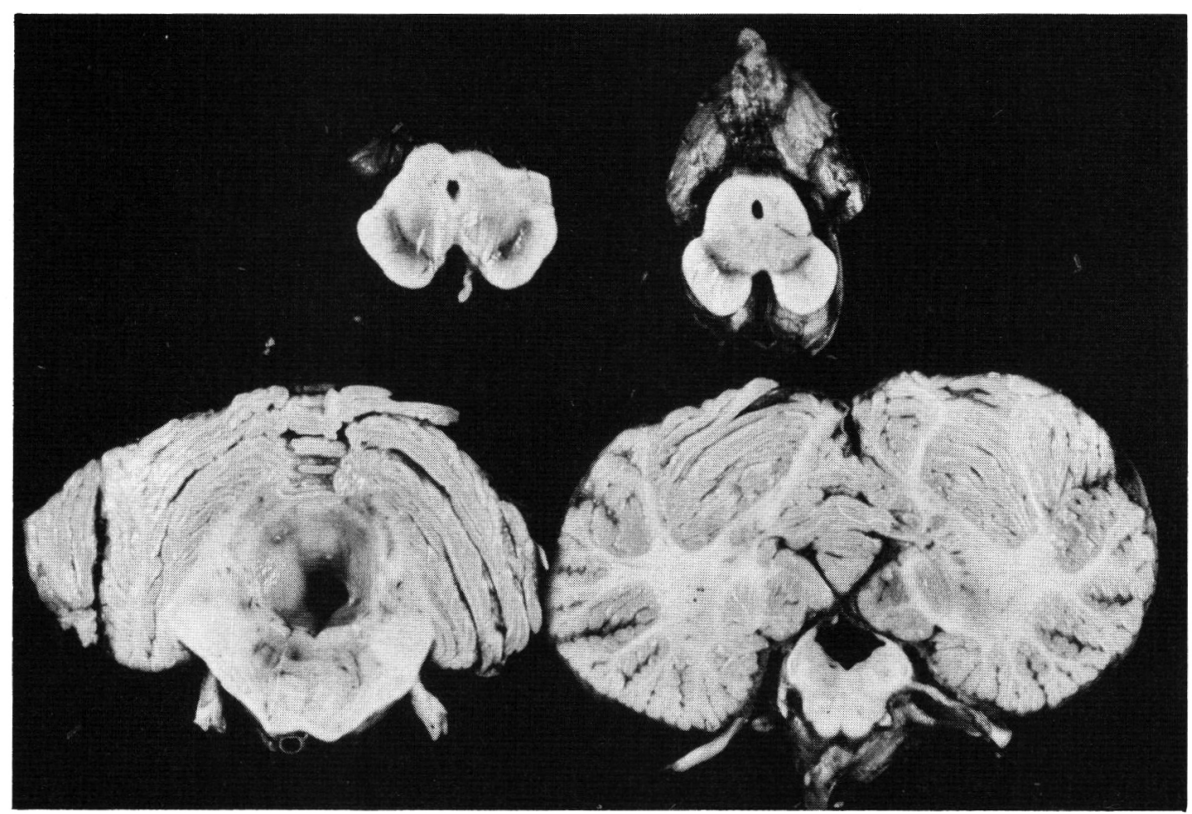

Figure 1 - The brain stem and cerebellum are small and the aqueduct and 4 th ventricle dilated. The middle and inferior cerebellar peduncles are small, the superior absent. cord, the dorsal and lateral columns appeared grey.

Microscopically, the following lesions were present (Fig. 2):
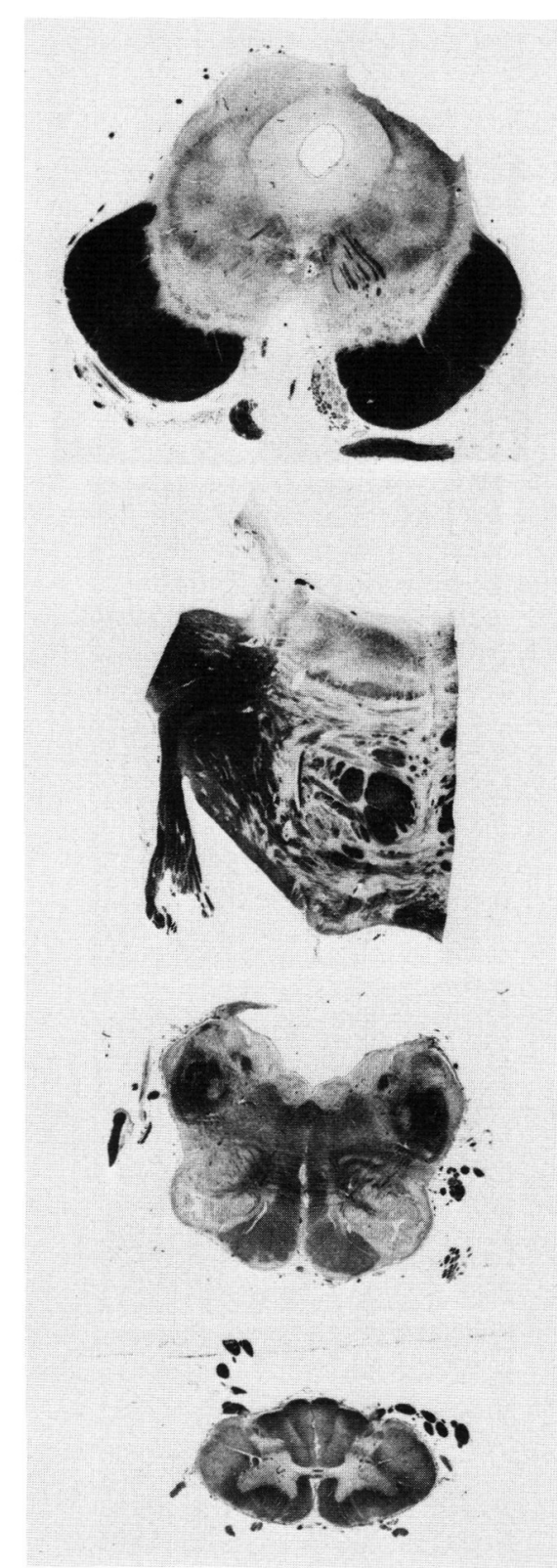

Figure 2 - From top to bottom:

Midbrain: Atrophy of superior cerebellar peduncle permits easy visualization of $3 \mathrm{rd}$ nerve in tegmentum. The cerebral peduncles are well myelinated.

Pons: Atrophy of the pontine nuclei and middle cerebellar peduncle makes the pyramidal tracts stand out.

Medulla: The inferior cerebellar peduncles are diminished and the pyramids and mediel lemniscus are pale.

Cervical spinal cord: Pallor of spinocerebellar and pyramidal tracts, partial pallor of dorsal columns. The roots are normal. Luxol fast blue-cresyl violet $x 2$. 
Spinal cord - Severe degeneration of dorsal and ventral spinocerebellar tracts, moderate degeneration of crossed pyramidal tracts, nearly complete nerve cell loss of Clarke's column, moderate degeneration of gracile and medial cuneate tracts.

Medulla - Severe degeneration of restiform bodies, marked cell loss and gliosis of vestibular and cochlear nuclei; inferior olives and their outflow intact.

Pons - Focal nerve cell loss, degeneration and gliosis of pontine nuclei, focal neuronal loss of locus ceruleus, atrophy of middle cerebellar peduncles.

Cerebellum - Degeneration of dentate nucleus and outflow, focal loss of Purkinje cells, axonal torpedoes, numerous amyloid plaques in cerebellar cortex.

Midbrain - Degeneration of superior cerebellar peduncles, focal neuronal loss in substantia nigra, focal neuronal loss and amyloid plaques in red nuclei.

Diencephalon - focal neuronal loss and amyloid plaques in thalamus and hypothalamus. Subthalamus normal.

Basal ganglia - Amyloid plaques in the striatum, claustrum and amygdaloid nucleus. Severe diffuse nerve cell loss and gliosis but no plaques in globus pallidus.

Cerebral hemispheres - Focal neuronal loss, astrocytosis and numerous amyloid plaques in all areas and all layers of the cerebral cortex including the hippocampus. No dendritic plaques or neurofibrillary tangles.

\section{Plaques}

Under the light microscope, these consisted of cloud-like cotton-wool deposits with deeper staining single large or multiple small centers. Many were visible with hematoxylin and eosin, but impregnated better with the Periodic Acid Schiff reagent. Congo red demonstrated the amyloid nature of these plaques. There was no congophil angiopathy. The Bodian silver method impregnated both the dense centers and lighter halo (Fig. 3). Abnormal neurites or neurofibrillary tangles were completely absent. Electron microscopic examination of ultrathin sections resolved the plaques into radiating fibrils with the dimensions of amyloid (Fig. 4). Structures with multiple centers were seen to be clusters of several plaques.

\section{DISCUSSION}

Since Gerstmann, Sträussler and Scheinker's (1936) report on the first family, two other patients have recently been described, one from France (Boudouresques et al, 1976) and the other from Southern Germany (Boellard and Schlote, 1980; Schlote et al, 1980). The symptomatology and pathological lesions in these cases closely match those of our patient. They not only presented with symptoms which did not quite fit the known types of cerebellar degeneration, but also showed significant brain disturbances, among which ocular pareses and swallowing difficulties were prominent. Deafness, present in our patient, was also mentioned by the other authors (Boudouresques et al, 1976; Boellard and Schlote, 1980). These symptoms are explained anatomically by the widespread nuclear degeneration in the brain stem, while any dementia is attributable to cortical involvement.

Clinically and pathologically the disease appears to belong to the hereditary "system degenerations". However, the presence of the amyloid plaques, similar to those occurring in Kuru and sometimes in CreutzfeldtJakob disease, alerted us to the fact that we might be dealing with a slow virus infection, even though the characteristic spongiform lesions were lacking in the brain and the clinical picture

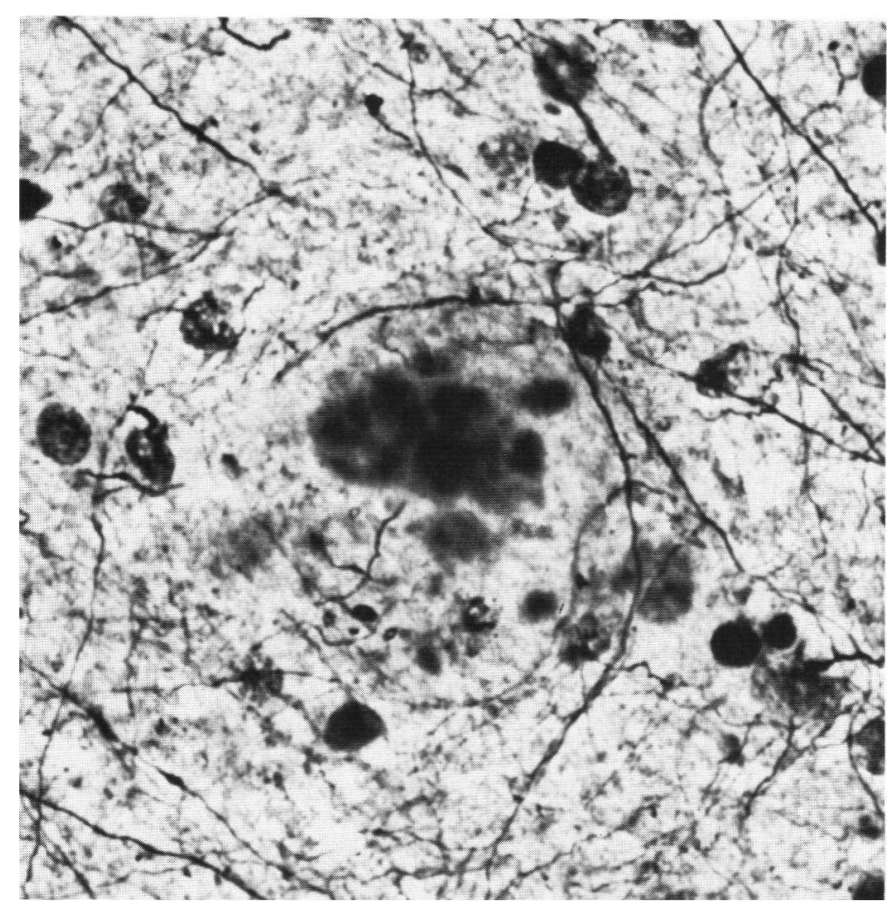

Figure 3 - Multicentrin amyloid plaque in cerebral cortex. Note absence of abnormal neurites. Bodian silver impregnation x 660 .

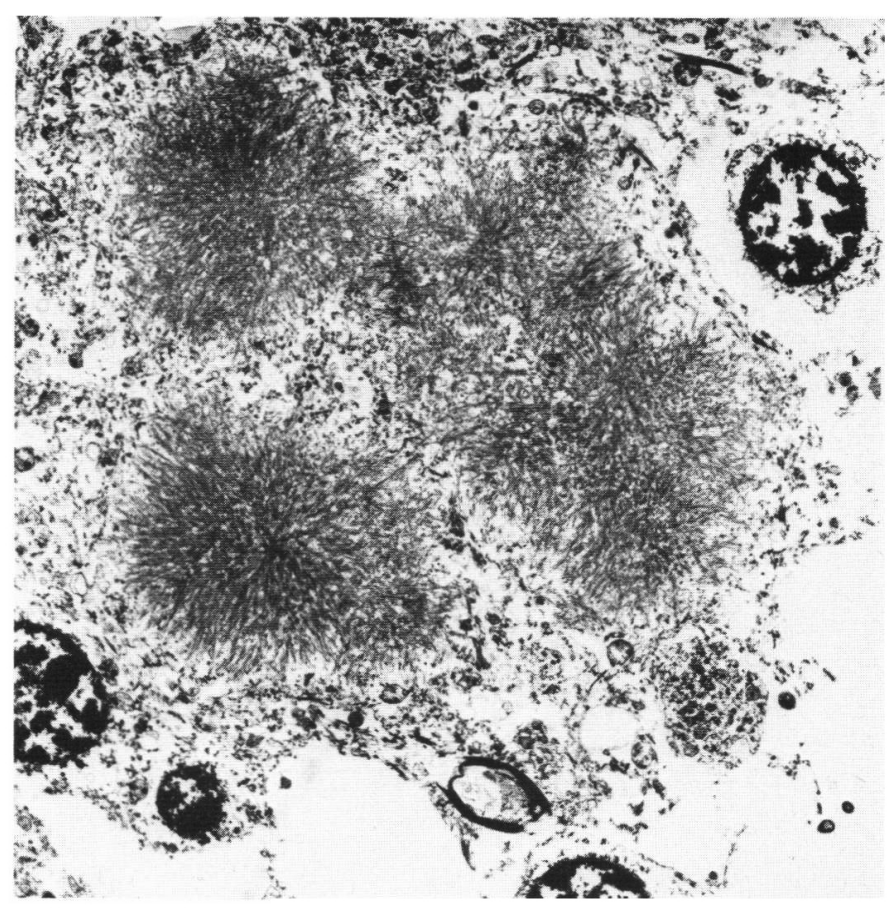

Figure 4 - Cluster of amyloid plaques with radiating fibrils in granule cell layer of cerebellum $x 4200$. 
was atypical. Accordingly, we have submitted most of the formalin-fixed brain to Dr. Gajdusek's Laboratory of the National Institutes of Health for animal transmission.

Masters, et al. (1981) have recently indicated the belief that the "Gerstmann Sträussler Syndrome", so named after the first authors, represents an atypical type or variant of CreutzfeldtJakob disease. In comparison with ordinary Creutzfeldt-Jakob disease without plaques, the Gerstmann Sträussler syndrome runs a longer course (13-132 months, mean 59 months) and causes death at a younger age (24-62 years, mean 48 years). The authors consider the multicentric or "Gerstmann Sträussler plaque" as intermediate between the unicentric amyloid plaque of Kuru and the dendritic plaque of Alzheimer's disease and therefore, assign all patients with such intermediate plaques to the "Gerstmann Sträussler Syndrome", even though their topographic lesions are quite different from those of the original family. Inoculation into animals of fresh brain tissue from cases who had a spongiform encephalopathy with amyloid plaques caused experimental spongiform ence- phalopathy, (Masters, 1981). Formalin fixed brain tissue from the 2 recent cases mentioned which resembled our patient, have not yet produced disease in animals, nor have other samples from patients without spongiform lesions, indicating some difference between the cases with and without spongiform changes.

We could not convince ourselves of a significant difference between the plaques in our case and those described for Kuru. Therefore, until the etiology is clarified, would recommend that the term "Gerstmann Sträussler Syndrome", if it is to be adopted at all, be applied only to those cases which clinically and pathologically simulate a hereditary spino-cerebellar degeneration.

\section{REFERENCES}

BOELLARD, J.W., SCHLOTE, W. (1980) Subakute spongiforme Encephalopathie mit multiformer Plaquebildung. Acta Neuropathol. 49: 205-212.
BOUDOURESQUES, J., TOGO, M. KHALIL, R., ALI CHERIF, A., PELLISSIER, J.F. and GOSSET, A. (1976) Dégénérescence spino-cérébelleuse tardive avec amyotrophies, comportant une attente pallido-luysienne sévère et des lesions histoloiques diffuses de sénilite (étude anatomo-clinique d'une cas avec discussion nosographique. Rev. Neurol. 123: 623-627.

BRAUNMÜHL, A. (1954) Über eine eigenartige hereditar-familiäre Erkrankung des Zentralnervensystems. Arch. Psychiat. Ztschr. Neurol. 191 : $419-444$.

GERSTMANN, D., STRÄUSSLER, E. and SCHEINKER, J. (1936) Über eine eigenartige hereditär-familiäre Erkrankung des Zentralnervensystems. Z. Neurol. 154: 736754.

MASTERS, C.L., GAJDUSEK, D.C. and GIBBS JR., J.R. (1981) Creutzfeldt-Jakob disease virus isolations from the Gerstmann Sträussler Syndrome: with an analysis of the various forms of amyloid plaque deposition in the virus-induced spongiform encephalopathies. Brain 104b; 559-588.

SCHLOTE, W., BOELLARD, F., SCHUMM and STOHR, M. (1980) GerstmannSträussler-Scheinker's disease. Electron microscopic observations on a brain biopsy. Acta Neuropathol. 52: 203.211.

SEITELBERGER, F. (1962) Eigenartige familiär-hereditäre Krankheit des Zentralnervensystems in einer Niederösterreichischen Sippe. Wien. klin. Wchnschr. 74: 687691. 